CAPÍTULO 6

\title{
BIOFERTILIZANTES EN COLOMBIA
}

Liliana Pérez Lavalle¹, Hernando José Bolívar Anillo², Anderson Díaz Pérez ${ }^{3}$

1 Profesor-Investigador. Programa de Microbiología y Coordinadora de Extensión Facultad de Ciencias Básicas y Biomédicas. Universidad Simón Bolívar, Barranquilla (Colombia).

lperez70@unisimonbolivar.edu.co

2 Profesor-Investigador. Programa de Microbiología, Universidad Simón Bolívar, Barranquilla (Colombia). hbolivar1@unisimonbolivar.edu.co

3 Profesor-Investigador. Programa de Microbiología, Universidad Simón Bolívar, Barranquilla (Colombia). adiaz72@unisimonbolivar.edu.co ID: orcid.org/0000-0003-2448-0953 


\section{RESUMEN}

En Colombia, el Instituto Colombiano Agropecuario (ICA) es la entidad encargada de regular la producción y comercialización de bioinsumos de uso agrícola. El presente estudio tuvo como objetivo describir los inoculantes biológicos producidos en el país que actúan como biofertilizantes. Para esto se consultó el listado de productos bioinsumos del ICA y se analizó a través Microsoft $\circledast$ Excel2010, y el programa SPSS 21.0® las variables, lugar de producción, ingredientes activos, tipo de formulación, actividad biológica y cultivos autorizados. Se encontró que la mayor producción de inoculantes se concentra en el departamento de Cundinamarca; asimismo, los principales microorganismos utilizados para el desarrollo de estos productos correspondieron a los hongos micorrizcos del género Glomus y Acaulospora, así como a las bacterias Azotobacter chroocoocum y Bradyrhizobium japonicum. La mayor parte de los inoculantes ostenta actividades biológicas varias y se presentan bajo formulación de tipo sólida. El arroz constituye el cultivo más frecuente de aplicación de los inoculantes. El trabajo permitió concluir que hay una nula producción de inoculantes biológicos en la mayoría de departamentos que conforman la región Caribe, en los cuales se producen cultivos de gran importancia para la seguridad alimentaria del país.

Palabras clave: Biofertilizantes, rizobacterias promotoras de crecimiento vegetal, micorrizas arbusculares, Colombia.

\section{ABSTRACT}

In Colombia, the Colombian Agricultural Institute (ICA) is the entity in charge of regulating the production and commercialization of bioinoculants for agricultural use. The present study had as objec- 
tive to describe the biological inoculants produced in the country that act as biofertilizers. For this we consulted the ICA bioinoculants products list and were analyzed through Microsoft ${ }^{\circledR}$ Excel 2010 and the program SPSS $21.0 \circledast$ the variables production location, active ingredients, type of formulation, biological activity and authorized crops. It was found that the highest production of inoculants is concentrated in the Cundinamarca department; furthermore, the main microorganisms used for these products development were the mycorrhizal fungi belonging to the genus Glomus and Acaulospora, also the bacteria Azotobacter chroocoocum and Bradyrhizobium japonicum. Most inoculants have various biological activities and are presented under a solid type formulation. Rice is the most frequent crop in which inoculants are applied. The work allowed concluding that there is not biological inoculants production in most of Caribbean Region departments in which great importance crops for the country food security are produced.

Key words: Biofertilizers, plant growth promoting rhizobacteria, arbuscular mycorrhizae, Colombia.

\section{INTRODUCCIÓN}

La fertilidad del suelo hace referencia a la capacidad del mismo de proporcionar nutrientes necesarios en cantidades adecuadas para el desarrollo de las plantas (Luna Martínez, et al., 2013). La Organización de las Naciones Unidas para la Alimentación y la Agricultura (FAO), en su estudio sobre el Estado de los Recursos de Tierras y Aguas, estableció que la vulnerabilidad de los sistemas agrícolas en el mundo es debida a la alta presión demográfica y prácticas productivas insostenibles (Rosset et al., 2011). Dada la necesidad de satisfacer la seguridad alimentaria humana, así como lograr en 
los sistemas de producción agrícola la disminución del uso de agroquímicos, los cuales representan altos costos para los agricultores e impactan negativamente el ambiente, el empleo de biofertilizantes constituye una alternativa para el desarrollo de una agricultura sostenible (Luna Martínez, Martínez Peniche, Hernández Iturriaga, Arvizu Medrano, y Pacheco Aguilar, 2013; Montañez, Blanco, Barlocco, Beracochea, y Sicardi, 2012)

Vessey describe que un biofertilizante "es una sustancia que contiene microorganismos vivos que cuando se aplica a la semilla, superficie de las plantas, suelo, rizósfera o al interior de las plantas promueve el crecimiento de la misma por el aumento en el suministro y disponibilidad de nutrientes primarios a la planta hospedera" (Vessey, 2003). En Colombia, "el Instituto Colombiano Agropecuario (ICA) es la entidad encargada de otorgar el registro a toda persona natural o jurídica que se dedique a realizar ensayos de eficacia, importar, producir, comercializar, usar y/o manejar bioinsumos de uso agrícola, así como de ejercer su control legal y técnico" (Aristizábal Sepúlveda, 2013). Dentro de estos bioinsumos se destacan los inoculantes biológicos, conformados principalmente por microorganismos promotores de crecimiento vegetal, los cuales incluyen tanto bacterias como hongos benéficos asociados de forma saprofítica o simbiótica con las raíces de las plantas, Pedraza et al. (2010; Camelo, Vera y Bonilla, 2011).

Las rizobacterias son conocidas por su sigla en inglés como PGPR (Plant Growth Promoting Rhizobacteria); son bacterias del suelo que colonizan las raíces de las plantas y ejercen efectos benéficos sobre estas. Este tipo de inoculantes biológicos (PGPR) son ampliamente utilizados como biofertilizantes, encuentran disponibles en el mercado en varias presentaciones (de Souza et al., 2013). 
Las PGPR cumplen una función importante en los suelos al transformar algunos nutrientes, presentes frecuentemente en formas menos disponibles, en formas biológicamente viables (Acevedo, Galindo-Castaneda, Prada, Navia, y Romero, 2014). Las PGPR pueden ser separadas en dos grupos: las PGPR extracelulares, las cuales habitan en la rizósfera, sobre el rizoplano o en los espacios intercelulares de la corteza de la raíz, y las PGPR intracelulares que viven dentro de las células de la raíz en estructuras nodulares especializadas (Kumar et al., 2015). De igual importancia son las micorrizas (asociación simbiótica entre el micelio de un hongo y las raíces de un vegetal) y otros géneros de hongos, los cuales pueden mejorar el estado nutricional de las plantas a través de diferentes mecanismos (Toro, Bazó, y López, 2008; Martínez y Pugnaire, 2009; Grageda-Cabrera, Díaz-Franco, Peña-Cabriales y Vera-Nuñez, 2012a; Aristizábal Sepúlveda, 2013).

Los tipos de micorrizas se toman como una alternativa de fertilización ecológica en los cultivos; las más conocidas son las ectomicorrizas y la endomicorrizas. Las ectomicorrizas invaden la raíz sin penetrar las células; por su parte, en las endomicorrizas el micelio penetra y se instala en el interior de las células de la raíz (Agerer, 2001; Treseder, 2004).

El desarrollo de inoculantes producidos localmente es deseable, ya que se adaptan a las condiciones locales (Wang et al., 2015; Rao, 2016). El objetivo del presente estudio es describir los tipos de inoculantes biológicos producidos en Colombia que actúan como biofertilizantes, proporcionando información sobre el lugar de producción, ingredientes activos, tipo de formulación, actividad biológica y cultivos autorizados. 


\section{ESTADO DEL ARTE}

Cada vez es más evidente la relevancia de los microorganismos en la naturaleza y su relación con el hombre, sobre todo en el potencial infinito que poseen para el mejoramiento de la agricultura (Rao, 2016; Wittwer, 2016).

Entre las prácticas para el fortalecimiento de la agricultura se encuentra el uso de microorganismos como biofertilizantes (Grageda-Cabrera et al., 2012a). Estos han sido ampliamente utilizados por productores de plántulas y empresas dedicadas a la producción de abonos orgánicos (Bojórquez et al., 2010). "Los biofertilizantes son preparados de microorganismos aplicados al suelo y/o planta con el fin de sustituir parcial o totalmente la fertilización sintética".

Los inóculos biológicos para la formulación de biofertilizantes pueden ser simples o mixtos. Los inóculos simples o mono-inóculos hacen referencia a un solo microorganismo; por su parte, los inóculos mixtos o co-inóculos representan dos o más microorganismos.

No todos los microorganismos con capacidad de promover el crecimiento vegetal se consideran biofertilizantes; algunos solo promueven el crecimiento por el control de organismos deletéreos, catalogándose como agentes de control biológico. Por el contrario, hay microorganismos como Burkholderia cepacia y Bacillus subtilis que actúan como biofertilizantes y biocontroladores (Vessey, 2003; Bojórquez et al., 2010). Entre los principales mecanismos que utilizan los microorganismos para ejercer su efecto biofertilizante se encuentran: la fijación biológica de $\mathrm{N}_{2}$, solubilización de fosfato, solubilización de potasio, producción de sideróforos, producción de reguladores de crecimiento, inducción de crecimiento y cambio en 
la morfología de las raíces, y estimulación de simbiosis beneficiosas para las plantas (Vessey, 2003; Grageda-Cabrera et al., 2012a; Kumar et al., 2015). Los biofertilizantes tienen un papel clave en la productividad y sostenibilidad del suelo, pero también en la protección del medioambiente como insumos ecológicos y rentables para los agricultores, contribuyendo de esta manera a la sostenibilidad de las granjas (Mohammadi y Sohrabi, 2012).

\section{Fijación biológica de $\mathbf{N}_{2}$}

El nitrógeno $\left(\mathrm{N}_{2}\right)$ es un elemento esencial que hace parte de muchas de las biomoléculas indispensables para la vida. A pesar de estar en altas concentraciones en la atmósfera, muchos organismos son incapaces de utilizarlo (Hoffman, Lukoyanov, Yang, Dean, y Seefel$d t, 2014)$. El nitrógeno atmosférico es convertido en formas asimilables para las plantas mediante el proceso de fijación biológica de nitrógeno, en el cual bacterias transforman el nitrógeno en amonio, utilizando un complejo enzimático denominado nitrogenasa; mediante este mecanismo se fijan, aproximadamente, dos terceras partes del nitrógeno en el planeta (Ahemad y Kibret, 2014).

La fijación del nitrógeno tiene un profundo impacto para los sistemas agrícolas, la economía, así como para la productividad de los ecosistemas naturales. Sin embargo, aunque el nitrógeno es un elemento de vital importancia para todos los organismos vivos, es a menudo un factor limitante de crecimiento en los ecosistemas del suelo (Kavadia, Vayenas, Pavlou y Aggelis, 2008; Ahemad y Kibret, 2014).

La mayor entrada de $\mathrm{N}_{2}$ al ecosistema terrestre es a través de la fijación biológica por acción de la enzima nitrogenasa e industrial del 
$\mathrm{N}_{2}$ atmosférico por el proceso Haber-Bosch, con una muy modesta entrada por la vía de deposiciones húmedas (lluvia) y secas (polvos) de partículas de $\mathrm{N}_{2}, \mathrm{NH}_{3}, \mathrm{NH}_{4}^{+}$y nitratos; pero el balance es frecuentemente negativo debido a la pérdida significativa de este elemento a través de la desnitrificación, erosión, lixiviación y volatilización (Herridge, Peoples, y Boddey, 2008; Hoffman et al., 2014).

El uso ineficiente de fertilizantes de nitrógeno contribuye a la contaminación de suelos y aguas subterráneas, lo que conlleva a graves peligros para la salud y el medioambiente; además, la fabricación de estos fertilizantes se basa en el uso de combustibles fósiles no renovables ( $1 \mathrm{~kg}$ de fertilizante de $\mathrm{N}$ requiere $38,000 \mathrm{Kj}$ de energía fósil), lo que trae consigo considerables emisiones de gases de efecto invernadero. La fabricación de fertilizantes nitrogenados requiere seis veces más energía que la necesaria para producir fertilizantes de fósforo y potasio (Orr, James, Leifert, Cooper, y Cummings, 2011; Santi, Bogusz, y Franche, 2013).

Entre los diversos pasos del ciclo del nitrógeno, la fijación biológica del nitrógeno es llevada a cabo por bacterias diazotróficas, que están ampliamente distribuidas en los taxones bacteria y arquea. La mayor parte (aproximadamente un 80 \%) de la fijación biológica de nitrógeno (FBN) es llevada a cabo por las asociaciones simbióticas específicas con leguminosas (ej. Rhizobium y Bradyrhizobium) y árboles no leguminosos (ej. Frankia). Sin embargo, algunas bacterias de vida libre del suelo (ej. Pseudomonas, Azospirillum y Azotobacter), en condiciones especiales, pueden fijar cantidades significativas de $\mathrm{N}_{2}\left(0\right.$ a $\left.60 \mathrm{~kg} \mathrm{~N} \mathrm{ha}{ }^{-1} \mathrm{años}^{-1}\right)$, que son de gran importancia para los sistemas agrícolas (Orr, James, Leifert, Cooper y Cummings 2011). 
Las bacterias fijadoras de nitrógeno de vida libre en el suelo incluyen: Cianobacterias, Proteobacterias, Arquea y Firmicutes, cuya población variará dependiendo de condiciones en el suelo, tales como temperatura, humedad, pH, contaminación, etc. (Zhan y Sun, 2011).

Aunque los fijadores de nitrógeno de vida libre no penetran los tejidos de las plantas, se establece una relación muy estrecha con las raíces, de tal manera que el nitrógeno fijado por las bacterias, que no es utilizado para su propio metabolismo, queda fácilmente disponible para las plantas (Goswami, Thakker y Dhandhukia, 2016).

Los organismos fijadores de nitrógeno son generalmente activos en la zona del suelo influenciada por las raíces de las plantas, probablemente debido a que la fijación biológica de nitrógeno son una serie de reacciones demandantes de energía (Alberty, 2005; Orr et al., 2011; Shridhar, 2012).

Rizobacterias promotoras del crecimiento vegetal pertenecientes a los géneros Acinetobacter, Alcaligenes, Arthrobacter, AzospiriIlium, Azotobacter, Bacillus, Beijerinckia, Burkholderia, Enterobacter, Erwinia, Flavobacterium, Rhizobium, Mycobacterium y Serratia, son conocidas por fijar nitrógeno molecular a través de asociaciones simbióticas y asimbióticas (Kumar et al., 2015), donde las especies pertenecientes a Azotobacter y Azospirillum son las más utilizadas como inoculantes en la agricultura. La aplicación Azotobacter chroococcum y Azospirillum brasilense en cereales han aumentado la producción de los cultivos (Goswami et al., 2016). Sin embargo, solo en Rhizobium ha sido demostrado el incremento de 
la producción de los cultivos debido a la fijación de $\mathrm{N}_{2}$. En el caso de las bacterias de vida libre fijadoras de $\mathrm{N}_{2}$ la promoción del crecimiento podría ser atribuida a otros mecanismos, semejantes a la producción de fitohormonas u otras actividades de promoción de crecimiento (Ahmad, Ahmad y Khan, 2008).

\section{Solubilización de fosfato}

El fósforo $(P)$ es un elemento esencial para todos los seres vivos, forma parte de las proteínas, ácidos nucleicos, membranas y moléculas energéticas, como el ATP, GTP y NADPH (Acevedo et al., 2014). El fósforo es, después del nitrógeno, el segundo nutriente mineral más limitante para el crecimiento de las plantas. Su reserva fundamental en la naturaleza es la corteza terrestre. Debido a la aplicación de fertilizantes los suelos agrícolas presentan buenas reservas de este macronutriente; no obstante, su disponibilidad para las plantas es baja debido a que se encuentra mayoritariamente en formas insolubles, y las plantas solo pueden absorberlo a partir de dos formas solubles, el fosfato monobásico $\left(\mathrm{HPO}_{4}^{-2}\right)$ y el fosfato dibásico (H2PO4-) (Vessey, 2003; Fernández y Rodríguez, 2005).

La concentración de $\mathrm{P}$ soluble en el suelo suele ser muy baja, normalmente a niveles de 1 ppm o menos (10 $\left.\mathrm{M} \mathrm{H}_{2} \mathrm{PO}_{4}^{-}\right)$. La fijación y precipitación de $\mathrm{P}$ en el suelo es altamente dependiente del $\mathrm{pH}$ y del tipo de suelo. De esta manera, en suelos alcalinos el fósforo se fija por el calcio, mientras que en suelos ácidos, el fósforo es fijado por óxidos e hidróxidos libres de aluminio y hierro, causando una baja eficiencia de los fertilizantes de fósforo solubles. Bacterias de los géneros Pseudomonas, Enterobacter, Bacillus, Proteus, Citrobacter, Klebsiella, Serratia y hongos filamentosos como AspergiIlus y Penicillium, solubilizan fosfato a través de la producción de ácidos orgánicos e inorgánicos, transformando el fósforo insoluble 
en fósforo disponible para las plantas (Rodríguez y Fraga, 1999). Por otra parte, las micorrizas contribuyen a la captación y transferencia de fósforo a la planta a partir del incremento del volumen de la raíz y actividad de polifosfatoquinasas y fosfatasas alcalinas (Sierra, 2008).

Diversos estudios han demostrado el beneficio de microorganismos solubilizadores de fosfato en diferentes cultivos (Kim, Jordan, y McDonald, 1997; Gurdeep y Reddy, 2015; Buono y Ulla, 2016). La inoculación de bacterias Pantoea cypripedii y Pseudomonas plecoglossicida junto con roca fosfórica, aumentó el crecimiento del cultivo de maíz y trigo en relación a la altura de los brotes, biomasa seca de ramas y de raíces, rendimiento de grano y captación total de P (Gurdeep y Reddy, 2015). Kim, Jordan y McDonald, 1997 encontró un aumento en el crecimiento de las plantas de tomate a los 35, 55 y 75 días con los tratamientos Enterobacter agglomerans, Glomus etunicatum y Glomus etunicatum + Enterobacter agglomerans en comparación con el control. Asimismo, halló una mayor absorción de $\mathrm{N}$ y $\mathrm{P}$ en plantas de tomate con la inoculación combinada de Glomus etunicatum (micorriza) y Enterobacter agglomerans (Kim et al., 1997). Buono y Ulla, 2016 evidenció que Pseudomonas fluorescens estimuló el crecimiento radicular e incrementó el contenido de fósforo foliar en el cultivo de tabaco y pimiento bajo condiciones controladas (Buono y Ulla, 2016).

\section{Solubilización de potasio}

La producción de cultivos es seriamente restringida por diversos factores, entre los que se destacan las malas hierbas, hongos, bacterias y virus. Los nutrientes minerales juegan un papel fundamental en la resistencia de las plantas al estrés (Wang, Zheng, Shen y 
Guo, 2013). El potasio (K) es el tercer nutriente más importante para las plantas después del nitrógeno y el fósforo, clave para su crecimiento, metabolismo y desarrollo; la falta de este elemento conlleva a un pobre desarrollo de las raíces, semillas pequeñas y un incremento a la susceptibilidad de las plantas a las enfermedades y pestes (Wang, Tang, Ge, Chen y Yong, 2013; Meena, Maurya y Verma, 2014).

El contenido de K de la mayoría de los suelos agrícolas oscila en un rango de $10-20 \mathrm{gKg}^{-1}$; sin embargo, entre el 90-98\% está incorporado en una red cristalina que no está directamente disponible para las plantas (Zörb, Senbayram y Peiter, 2014). Esta estructura compleja del K en el suelo puede ser solubilizada por microorganismos conocidos como solubilizadores de potasio y, de esta manera, quedar disponible para las plantas (Meena, Maurya y Verma, 2014).

Una amplia gama de géneros de bacterias se han reportado como solubilizadoras de K, entre las que se destacan Pseudomonas, Burkholderia, Acidothiobacillus, Bacillus y Paenibacillus; entre los hongos las micorrizas arbusculares y especies del género AspergiIlus, Penicilliumy Cladosporium también poseen dicha capacidad (Parmar y Sindhu, 2013; Meena et al., 2014). La falta de K en un cultivo incrementa la susceptibilidad de este a enfermedades $y$, por lo tanto, aumenta la necesidad de aplicación de pesticidas (Zörb, Zembayram y Peiter, 2014). Por tanto, inoculantes microbianos con capacidad de solubilizar $\mathrm{K}$ a partir de minerales y rocas son una alternativa para mejorar el crecimiento y rendimiento de las plantas, además de ser económicamente viables y respetuosos con el medioambiente (Meena et al., 2014). 


\section{Producción de sideróforos}

El hierro es uno de los minerales más abundantes en la superficie de la tierra y es un micronutriente esencial para la mayoría de los seres vivos. Este elemento es requerido como grupo prostético o cofactor para diversas enzimas que participan en diversas vías metabólicas (Greenshields, Liu, Feng, Selvaraj y Wei, 2007). A pesar de su abundancia en los suelos, el hierro no es fácilmente asimilado por las plantas debido a su rápida oxidación de $\mathrm{Fe}^{2+}$ a $\mathrm{Fe}^{3+}$, y posterior formación de hidróxidos insolubles (Aguado-Santacruz, Moreno-Gómez, Jiménez-Francisco, García-Moya, y Preciado-Ortiz, 2012).

El pH del suelo influye de manera sustancial en la disponibilidad del hierro, presentándose una baja solubilidad a medida que aumenta el pH (Kaiser y Guggenberger, 2000; Acevedo-Sandoval, Ortiz-Hernández, Cruz-Sánchez, y Cruz-Chávez, 2004). La deficiencia de hierro ocasiona clorosis (amarillez en el follaje) y baja productividad en las cosechas (Encinas y García, 1997).

Las PGPR producen compuestos de bajo peso molecular, denominados sideróforos, que actúan como quelantes (secuestrantes) del hierro en la rizósfera. Estos compuestos solubilizan el hierro haciéndolo asimilable para las plantas y mejorando, por ende su crecimiento (Camelo et al., 2011; Vejan, Abdullah, Khadiran, Ismail, y Nasrulhaq Boyce, 2016). La pioverdina es un ejemplo de sideróforo sintetizado por Pseudomonas a la cual se le ha atribuido la capacidad de incrementar el rendimiento de cebada, maíz y trigo (Höfte, Seong, Jurkevitch y Verstraete, 1991). 


\section{Producción de reguladores de crecimiento}

Las fitohormonas auxinas, ácido abscísico, citoquininas, giberelina y etileno son moléculas que derivan de vías metabólicas esenciales de las plantas y ejercen su acción localmente, alrededor del sitio de síntesis o en tejidos distantes, jugando un papel fundamental en las respuestas a estrés biótico y abiótico (Vega-Celedón, Canchignia Martínez, González y Seeger, 2016). Las plantas, cuando se encuentran en condiciones adversas, son capaces de ajustar los niveles de sus fitohormonas con el objetivo de disminuir los efectos negativos que le puedan ocasionar dichas condiciones (Glick, 2012). Los microorganismos rizosféricos pueden producir o metabolizar estos compuestos alterando el balance hormonal de la planta, impactando directamente su crecimiento y respuesta al estrés (Dodd, Zinovkina, Safronova y Belimov, 2010; Glick, 2012). Las plantas responden a fitohormonas en la rizósfera que hayan sido suplementadas externamente, o producidas por los microorganismos que habitan en esta zona (Höfte, Seong, Jurkevitch y Verstracte, 1991).

La capacidad de producir fitohormonas ha sido descubierta en muchos microorganismos promotores de crecimiento vegetal, entre los que cabe mencionar: Pseudomonas aeruginosa, Azotobacter vinelandii, pantoea agglomerans, Bacillus subtilis, Azospirillum brasilense, bacillus pumilus, Achromobacter xylosoxidans, Rhizopogon roseolus y Trichoderma (Kudoyarova, Arkhipova y Melent'ev, 2015).

Algunas de las funciones reguladoras del crecimiento vegetal de las fitohormonas, producidas por microorganismos rizosféricos, incluyen la división y expansión celular, alargamiento celular, alargamiento del tallo, crecimiento de las raíces, activación del crecimien- 
to de los brotes, desarrollo de las ramas, la promoción o el retraso en la senescencia foliar y la producción de clorofila; todas estas funciones pueden ser aprovechadas con el uso de estos microorganismos en biofertilizantes (Wong, Tan, Ge, Chen, y Yong, 2015).

\section{Inducción de crecimiento y cambio en la morfología de las raíces}

Las rizobacterias promotoras de crecimiento vegetal potencializan la absorción de nutrientes en las plantas a través del incremento de la superficie y longitud de las raíces (Vessey, 2003). Bacterias diazotróficas de vida libre como Azotobacter chroococcum y Azomonas macrocytogenes, han ocasionado un aumento en la longitud de las raíces de trigo a través de la producción de fitohormonas como ácido-indol-3-acético (IAA) y giberelinas (Pati, Sengupta y Chandra, 1995).

De igual manera, otras fitohormonas como las auxinas y citoquinas, producidas por las PGPR, se han visto involucradas en el desarrollo de las raíces (Ortíz-Castro, Contreras-Cornejo, Macías-Rodríguez, y López-Bucio, 2009). La inoculación de cepas de Azospirillum sp en diferentes cultivos ha provocado un aumento en el número y densidad de pelos radicales, lo cual le permite a la planta acceder a más nutrientes (de Souza et al., 2013). Asimismo, las micorrizas favorecen la captación de nutrientes y agua de las plantas, por el incremento de la superficie de absorción de la raíz, lo cual le permite explorar un volumen mayor de suelo (Dell'Amico, Rodríguez, Torrecillas, Morte, y Sánchez-Blanco, 2002; Molina, Mahecha, Medina y others, 2005; Noda, 2009).

Los aislados micorrízicos del filo Glomeromycota han contribuido a la nutrición de N y P en alfalfa (Munkvold, Kjøller, Vestberg, Rosen- 
dahl y Jakobsen, 2004). Se considera que las hifas de los hongos micorrízicos permiten extender el campo de absorción de la raíz; de igual manera, exudados y compuestos orgánicos volátiles emitidos por esporas Gigaspora margarita han promovido significativamente la formación de raíces laterales en $L$. japonicus tipo salvaje (Fortin et al., 2002; Frey-Klett, Garbaye y Tarkka, 2007).

\section{Estimulación de simbiosis fúngicas}

Algunas PGPR pueden estimular la relación entre planta y simbiontes fúngicos, mejorando con ello el crecimiento de la planta por una mayor adquisición de nutrientes, mediante interacciones directas o indirectas con las raíces de las plantas (Jeffries, Gianinazzi, Perotto, Turnau, y Barea, 2003). La mayoría de las raíces de las plantas están colonizadas por hongos micorrízicos, y su presencia generalmente estimula el crecimiento de las plantas (Jeffries et al., 2003; Artursson, Finlay y Jansson, 2006). Estas bacterias ayudantes de la micorrización son conocidas por su sigla en inglés como MHB (Mycorrhization Helper Bacteria-Bacterias ayudantes de la micorrización) (Duponnois y Garbaye, 1991). Las MHB promueven el establecimiento de la simbiosis, estimulando la extensión micelial, incrementando el contacto y colonización del hongo con la raíz, y reduciendo el impacto de factores ambientales adversos para el micelio de los hongos micorrícicos. Entre los géneros catalogados como MHB se encuentran: Agrobacterium, Azospirillum, Azotobacter, Burkholderia, Bradyrhizobium, Enterobacter, Pseudomonas, Klebsiella, Rhizobium, Bacillus, Brevibacillus, Paenibacillu, Rhodococcus, Streptomyces y Arthrobacter (Frey-Klett, Garbaye y Tarkka 2007).

La inoculación de Pseudomonas fluorescens incrementó la colonización micorrízica y la producción del cultivo de tomate (Gamalero 
et al., 2004). Khaitov evidenció que la bacteria fijadora de nitrógeno Azotobacter chroococcum mejoró la colonización de la micorriza arbuscular Glomus mosseae en la raiz de frijol común Phaseolus vulgaris L. Tanto la micorriza como Azotobacter chroococcum aumentaron en este estudio la biomasa de los tejidos vegetativos (Khaitov, Patiño-Ruiz, Pina y Schausberger, 2015). Xie et al. (1995) demostraron qué factores de nodulación producidos por una cepa Bradyrhizobium japonicum estimularon la producción de flavonoides por plántulas de soya (Glycine Máx.) y la formación de micorrizas. Los microorganismos actúan como biofertilizantes utilizando uno o combinando varios de los mecanismos anteriormente descritos.

\section{Formulaciones de biofertilizante}

Los biofertilizantes frecuentemente se preparan como carriers (soporte) que contienen microorganismos eficaces (Accinelli, Saccà, Abbas, Zablotowicz y Wilkinson, 2009). Entre los criterios que debe cumplir un soporte se encuentran: 1) El apoyo al crecimiento, supervivencia y liberación del microorganismo; 2) Absorción de humedad, buena aireación y capacidad tampón; 3) No tóxico y respetuoso con el medioambiente; 4) Fácil de fabricar, esterilizar, almacenar y manipular en campo, 5) Debe ser económico (Wang, Zheng, Sen y Guo, 2015).

La materia prima del soporte y el tipo de formulación varía mucho, pero generalmente son económicas y naturalmente abundantes. Entre estos materiales se encuentran la turba, bagazo, estiércol animal, compost de polvo de coco, lombricompost, perlita, rocas de fosfato, carbón de leña y lignito (Stephens y Rask, 2000).

Existen dos tipos principales de formulaciones: 1) Sólidas o secas: 
pueden ser en polvo y granular; 2) Líquidas: principalmente concentrados en suspensión y emulsión (Jones y Burges, 1998).

\section{METODOLOGÍA}

En la página web del Instituto Colombiano Agropecuario (ICA) se consultó el listado de Productos Bioinsumos con fecha de actualización a septiembre 23 de 2016 («Instituto Colombiano Agropecuario-ICA», s. f.). De dicho listado se tomó solo la información correspondiente a los bioinsumos catalogados como inoculantes biológicos, excluyendo, asimismo, aquellos inoculantes con actividad biológica para proceso de compostaje. A través de Microsoft $®$ Excel 2010 y el programa SPSS $21.0 ®$, se analizaron las siguientes variables: última resolución ICA, lugar de producción, ingredientes activos, tipo de formulación, actividad biológica y cultivos autorizados.

\section{RESULTADOS}

\section{Resolución ICA}

Con excepción de los inoculantes con actividad biológica para el proceso de compostaje, en el listado de bioinsumos del ICA se encuentran en total 47 inoculantes biológicos, de los cuales el $85,1 \%$ cuenta con resolución del ICA y el $14,9 \%$ no tiene resolución vigente.

\section{Distribución de la producción de inoculantes en Colombia}

Como se aprecia en la llustración 1, la producción de inoculantes biológicos en Colombia se concentra en el departamento de Cundinamarca con un 48,9\%, seguido por los departamentos del Tolima y Antioquía con un 14,9\% cada uno. 


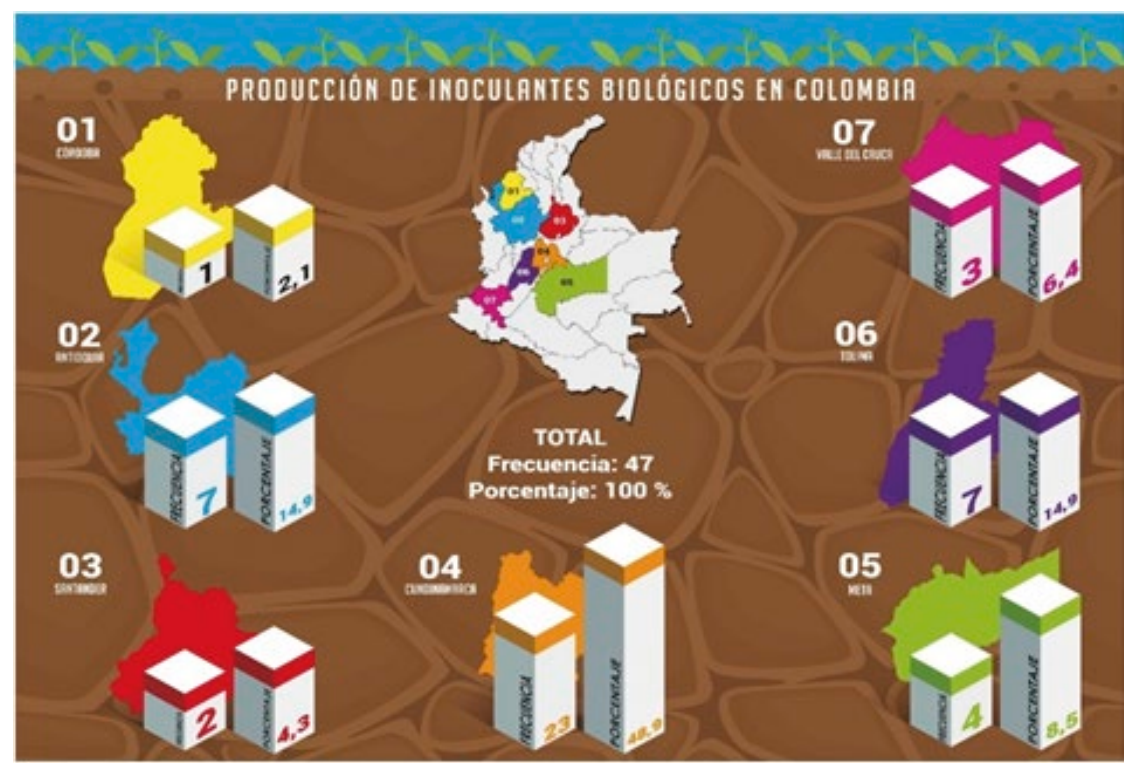

\section{Producción de inoculantes biológicos en Colombia}

Fuente: Elaboración propia (2017). Datos tomados del Instituto Colombiano Agropecuario (ICA); se consultó el listado de Productos Bioinsumos con fecha de actualización a septiembre 23 de 2016 («Instituto Colombiano Agropecuario-ICA», s. f.).

\section{Características de los inoculantes biológicos}

En relación a otras características de los inoculantes, el 51,1\% corresponde a inóculos mixtos y el 48,9\% a inóculos simples. De acuerdo al Gráfico 1, los inoculantes biológicos en Colombia poseen una actividad biológica variada en un 55,3\%, mientras que el $29,8 \%$ y el $14,9 \%$ presentan como mecanismo de acción la fijación biológica de nitrógeno y la solubilización de fosfato respectivamente. En cuanto al tipo de formulación, el 53,1 \% de los inoculantes son sólidos y el 46,9 \% tienen una presentación líquida. 
PRODUCTOS DE CONFITERÍA NUTRACÉUTICA Y BIOFERTILIZANTES.

Una opción empresarial para cultivadores de frutas y hortalizas

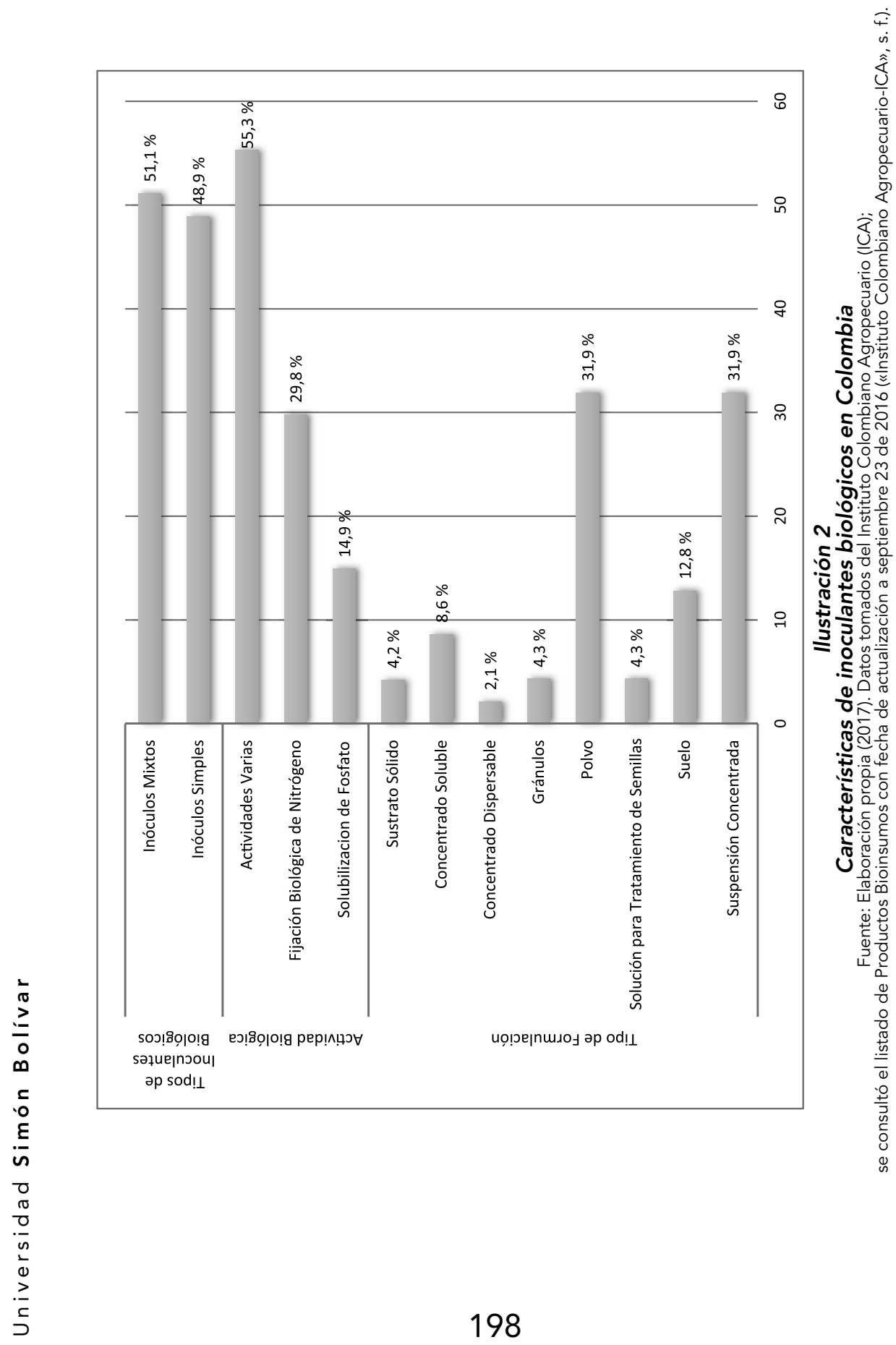




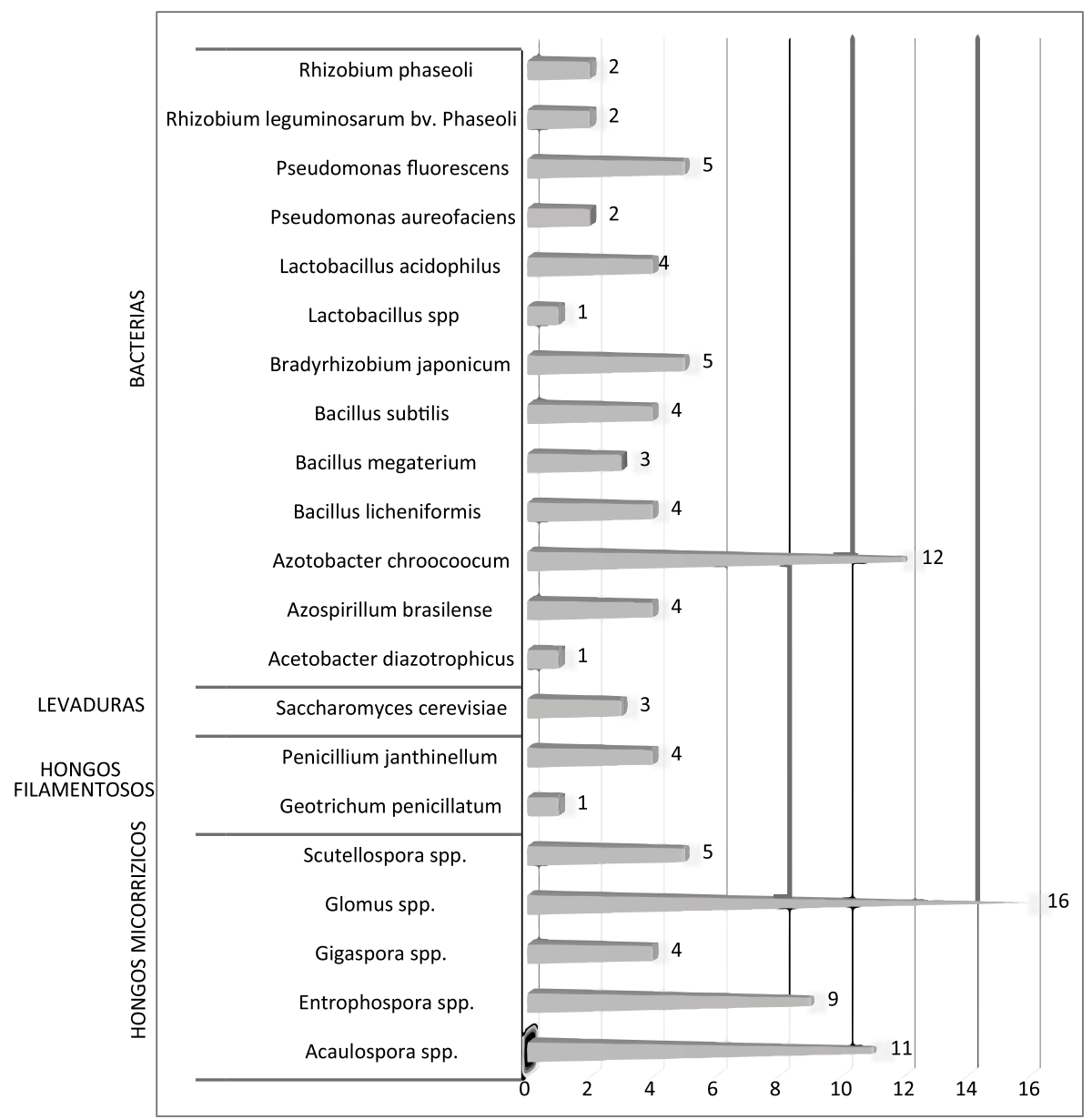

\section{Ilustración 3}

Microorganismos empleados para el desarrollo

\section{de inoculantes biológicos registrados ante el ICA}

Fuente: Elaboración propia (2017). Datos tomados del Instituto Colombiano Agropecuario (ICA) se consultó el listado de Productos Bioinsumos con fecha de actualización a septiembre 23 de 2016 («Instituto Colombiano Agropecuario - ICA», s. f.).

\section{Microorganismos empleados en el desarrollo de inoculantes biológicos}

Por otra parte, en la Gráfico 2 se puede observar que los grupos microbianos utilizados para la producción de inoculantes corresponden a: hongos micorrízicos, hongos filamentosos, levaduras y 
bacterias. Dentro de los más empleados en el desarrollo de inoculantes biológicos se encuentran los hongos micorrízicos del género Glomus y Acaulospora, y las bacterias Azotobacter chroocoocum, Bradyrhizobium japonicum y Pseudomonas fluorescens.

\section{Cultivos autorizados}

En relación a los cultivos de aplicación, los inoculantes biológicos se encuentran principalmente dirigidos para cultivos de gramíneas como el arroz y el pasto. De igual manera, a leguminosas como la soya y otros cultivos como el café y el algodón (Ver Gráfico3).

\section{Discusión}

La mayor parte de las empresas productoras de inoculantes biológicos en Colombia se concentran en tres departamentos, destacándose Cundinamarca y Antioquia como unas de las regiones más competitivas del país. Esta situación se relaciona con el hecho de que la producción de inoculantes requiere de tecnología e infraestructura necesarias, que permitan una producción a gran escala y con la mayor calidad posible (Grageda-Cabrera, Díaz-Franco, Peña Cabriales y Vera-Nuñez, 2012a). De igual manera, se aprecia que la mayor parte de departamentos que conforman la región Caribe colombiana, donde se obtienen diferentes cultivos como maíz, yuca, ñame, banano, guayaba, limón, mango y palma, no cuentan con empresas registradas ante el ICA para la producción y comercialización de inoculantes biológicos (Díaz et al., 2013). Lo anterior constituye una oportunidad para que agricultores, empresarios e institutos de investigación desarrollen inoculantes dirigidos a las necesidades de los cultivos de la región Caribe, ya que la utilización de microorganismos nativos para la elaboración de biofertilizantes presenta mayores posibilidades de efectividad en el campo, debido a que dichos microorganismos se encuentran adaptados a las condiciones del suelo (Bojórquez et al., 2010). 


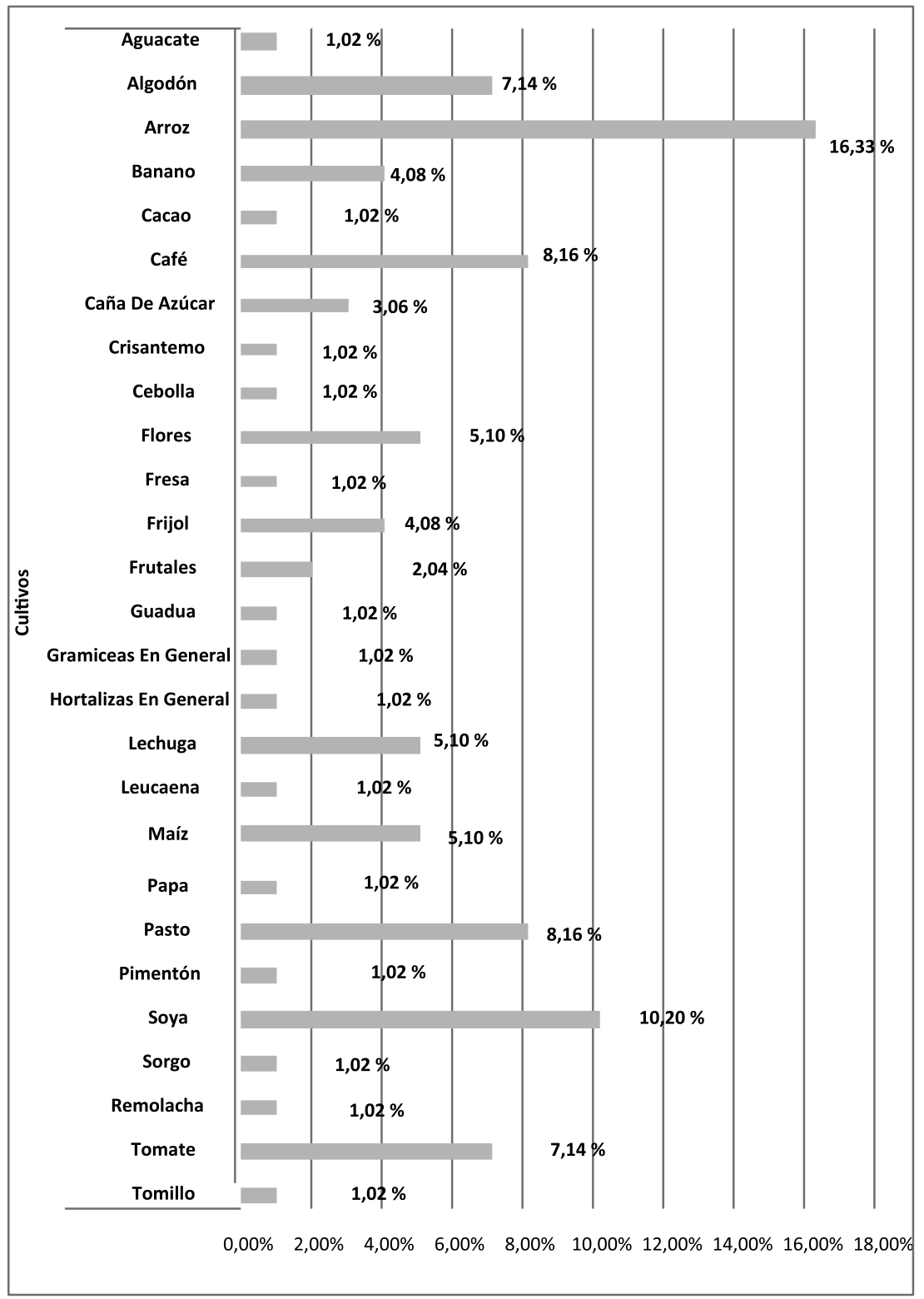

\section{Ilustración 4}

Número de inoculantes dirigidos por cultivo

Fuente: Elaboración propia (2017). Datos tomados del Instituto Colombiano Agropecuario (ICA); se consultó el listado de Productos Bioinsumos con fecha de actualización a septiembre 23 de 2016 («Instituto Colombiano Agropecuario-ICA», s. f.). 
En relación a los inóculos mixtos, se considera que los beneficios a la planta se deben probablemente al efecto sinérgico que los microorganismos ejercen (Bashan, 1998; Cowan, 1999; Stephens y Rask, 2000). No obstante, la interacción de los microorganismos dentro de estas formulaciones (mixtas) es en gran parte desconocida (Bashan, de-Bashan, Prabhu, y Hernandez, 2014). El desarrollo de tales inoculantes requiere tener en cuenta la compatibilidad entre los microorganismos implicados, interacción con las plantas, eficiencia de sus efectos, tasa de crecimiento cuando interactúan, formación potencial de biofilm y dificultades para realizar el cultivo debido a los diferentes requerimientos nutricionales $u$ otras condiciones de crecimiento in vitro (Bashan,de-Bashan, Prabhu y Hernández, 2014). Los más frecuentes en el listado del ICA fueron los productos a base de géneros de hongos micorrízicos, entre los cuales se destacan: Glomus, Acaulospora, Entrophospora, Scutellospora, los cuales exhiben actividades biológicas varias. Los hongos micorrízicos contribuyen al estado nutricional de la planta a partir del incremento del volumen de exploración de las raíces, lo que conlleva a una mayor captación de agua y nutrientes como $\mathrm{P}$, $\mathrm{N}, \mathrm{K}$ y Ca. Asimismo, proveen protección contra ciertos patógenos e incrementan la tolerancia a los cambios de temperatura y acidez, y mejoran la estructura del suelo (Grageda-Cabrera, Díaz-Franco, Peña-Cabriales, y Vera-Nuñez, 2012b).

Los co-inóculos (mixtos), a partir de hongos micorrízicos registrados ante el ICA, están autorizados para una variedad de cultivos, entre los que se encuentran: frutales, hortalizas, gramíneas, cultivos de café y algodón. El género Glomus fue uno de los más empleados en los inoculantes biológicos producidos en Colombia. Glomus spp, es el género más grande de micorrizas arbusculares; 
su efecto sobre la nutrición de las plantas se debe al transporte de iones minerales, principalmente el fósforo (Tsvetkov, Dzhambazova, Kondakova y Batchvarova, 2014). La inoculación con Glomus sp. Zac-19 afectó positiva y significativamente todas las variables de crecimiento y concentración de $\mathrm{P}$ en cítricos micropropagados (González-Chávez, Ferrera-Cerrato, Villegas-Monter, y Oropeza, 2000). Especies de Glomus como G. mosseae y G. geosporum han demostrado la capacidad de mejorar las relaciones hídricas de mandarina bajo condiciones de agua y sequía, incrementando variables como el crecimiento, carbohidratos, características fotosintéticas y actividades de enzimas antioxidantes $(\mathrm{Wu}, \mathrm{Zou}, \mathrm{Xia}, \mathrm{y}$ Wang, 2007). Glomus versiforme BGC GD01C (Gv) aumentó la actividad de la fosfatasa ácida del suelo y, por consiguiente, el crecimiento de Solanum nigrum a partir de un mayor incremento en la adquisición de $\mathrm{P}$ en suelos adicionados con cadmio, lo cual resalta la potencialidad de esta especie para fines de fitorremediación en suelos contaminados con cadmio (Liu et al., 2015). La inoculación con Bacillus megaterium (bacteria solubilizadora de fosfato) y Glomus intraradices mejoró la micorrización y la biomasa del maíz (Bidondo et al., 2012).

Por otra parte, Acaulospora es el único género de la familia Acaulosporaceae; varios estudios han demostrado el efecto de esta micorriza arbuscular en diferentes cultivos. Acaulospora spinosa y A. scrobiculata mostraron una respuesta positiva en términos de niveles de colonización de raíces, formación de esporas, biomasa vegetal y rendimiento de grano en ocho variedades de arroz (Ammani y Rao, 1996; Taylor, Walker y Bending, 2014). En otro estudio se inoculó Acaulospora spinosa XJ27 en raíces de tomate produciendo un aumento en la biomasa, cantidad de licopeno y rendimiento de las plantas (Ke et al., 2016). 
En relación a los co-inóculos bacterianos encontrados en el listado del ICA, se destacan los conformados por Azotobacter choroococcum, Pseudomonas fluorescens, Bacillus licheniformis, Bacillus subtillis y Bacillus megaterium. Las formulaciones polimicrobianas que contienen diversas bacterias rizosféricas con diferentes funciones tales como fijación de nitrógeno, solubilización de fosfato y biocontrol son atractivas, ya que se pueden aprovechar estos mecanismos para promover el crecimiento de diferentes tipos de cultivo, pero sus formulaciones son técnicamente complejas (Reddy y Saravanan, 2013). Un inoculante que contenía Klebsiella pneuminiae, Pseudomona fluorescens y Citrobacter freundii fue utilizado para estimular el cultivo de arroz, observándose un incremento del 20-30 \% en la producción y una disminución de la utilización de úrea en un $50 \%$, lo cual disminuye los costos de producción (Reddy y Saravanan, 2013). Por otro lado, es probable que la mayoría de los casos de control biológico de origen natural resulten de mezclas de microorganismos en lugar de altas poblaciones de un solo antagonista, por lo tanto, la introducción de una mezcla de agentes de biocontrol podría ser más semejante a lo que ocurre en la naturaleza (Raupach y Kloepper, 1998). Bacillus pumilus, Bacillus subtilis y Curtobacterium flaccumfaciens fueron evaluados solos y en combinación contra fitopatógenos de pepino, estableciéndose que hubo una tendencia general en todos los experimentos hacia una mayor supresión contra los fitopatógenos de pepino, usando la mezcla de estos agentes de biocontrol (Raupach y Kloepper, 1998).

Por otra parte, de manera individual y haciendo parte de inóculos mixtos, se resalta como bacteria más empleada en la elaboración de inoculantes biológicos con registro ICA a Azotobacter choroococcum, este es un bacilo Gram negativo diazotrófico no simbió- 
tico de vida libre, que habita principalmente en suelos neutrales o alcalinos, cuyo uso como biofertilizante fue propuesto por primera vez por Gerlach y Voel en 1902 con el objetivo de suplementar el suelo con nitrógeno (Sethi y Adhikary, 2012; Wani, Chand, Wani, Ramzan y Hakeem, 2016). Se ha reportado que Azotobacter posee una alta capacidad de reducción del acetileno y es capaz de fijar entre 2-15 mg N/g de glucosa consumida (Sethi y Adhikary, 2012). Sin embargo, la capacidad de estimular el crecimiento de las plantas por Azotobacter no solo está ligado a su capacidad de fijar nitrógeno, otros dos mecanismos parecen estar involucrados en este proceso, como es la producción de fitohormonas (alteran el crecimiento y morfología de las plantas) y la capacidad de reducir nitratos (incrementa la acumulación de nitrógeno en las plantas) (Wani, Chand, y Ali, 2013; Wani et al., 2016).

Azotobacter chroococcum posee una alta tasa de crecimiento y capacidad de tolerar diferentes variables medioambientales, lo que le permite ser utilizada como biofertilizante (Sethi y Adhikary, 2012). En este sentido, Kızılkaya evaluó la respuesta de rendimiento y las concentraciones de nitrógeno del trigo de primavera (Triticum aestivum), inoculando las semillas con 10 cepas nativas de Azotobacter chroococcum aisladas en Anatolia del Norte, Turquía y A. chroococcum cepa Beijerinck 1901 (DSMZ 2286). Los resultados mostraron que todas las cepas tuvieron un efecto positivo sobre el rendimiento y concentración de $\mathrm{N}$ en el trigo. No obstante, una de las cepas nativas ensayadas identificada como $A$. chroococcum RK49 fue la que mostró mayor efecto en el rendimiento e incremento de la producción del grano, lo que sugiere que el uso de cepas nativas podría ser adecuado para la producción de biofertilizantes (Kızılkaya, 2008). Por su parte Milošević, Tintor y Cvijano- 
vić, (2012) evaluaron el efecto de la inoculación con Azotobacter chroococcum cepa 86 sobre el rendimiento del trigo y la calidad de la semilla, reportando que la inoculación incrementa la energía de germinación del 1 al 9 \% y mejora la viabilidad de la semilla de 2 al $8 \%$, lo que sugiere la importancia económica y ecológica de la aplicación de este microorganismo.

La fijación simbiótica de nitrógeno es un componente vital en las prácticas agrícolas. En condiciones limitadas de nitrógeno, los rizobios pueden inducir la formación de estructuras especializadas en raíces o tallos de su hospedero, dentro del cual se convierte en su forma endosimbiótica, el bacteroide, el cual convierte el nitrógeno en amonio, quedando este último disponible para la planta (Broughton, Zhang, Perret y Staehelin, 2003). Entre los rizobios, Bradyrhizobium japonicum es la especie de mayor importancia en la agricultura, debido a su capacidad de formar nódulos en las raíces de soya (Glycine max), leguminosa de alto valor nutricional (Kaneko et al., 2002). Como el nitrógeno es un factor limitante para el desarrollo y la productividad de la soya, la actividad del Bradyrhizobium es fundamental, tanto desde el punto de vista económico como ambiental (Panzieri, Marchettini y Hallam, 2000). B. japonicum ha sido ampliamente utilizado para producir bioinoculantes líquidos y sólidos para su aplicación en semillas antes de la siembra (Menéndez et al., 2014). El costo del inóculo es relativamente bajo, y una vez introducidas al suelo las bacterias pueden persistir durante algún tiempo (3-4 años), lo que conlleva a una reducción de la utilización de fertilizantes químicos (Panzieri, Marchettini y Hallam, 2000). Los suelos usualmente están desprovistos de B. japonicum al menos que la soya sea cultivada durante 5 o más años, por lo que 
la inoculación de las semillas es indispensable antes de la siembra, principalmente si el cultivo se realiza por primera vez (Solomon, Pant y Angaw, 2012). Este mismo estudio estableció que la inoculación de la soya con B. japonicum aumenta el rendimiento en el número de vainas por planta, el número de semillas por vaina, el rendimiento de la semilla, el peso de mil semillas, la biomasa seca por encima del suelo y la absorción total de nitrógeno (Solomon, Pant y Angaw, 2012).

Las Pseudomonas son un importante componente de la rizósfera y algunas especies pueden actuar como rizobacterias promotoras del crecimiento vegetal, donde estas especies ejercen su efecto beneficioso a través de diversos mecanismos, pero principalmente por la exclusión activa de patógenos de la rizósfera; como es el caso de Pseudomonas fluorescens, la cual es capaz de solubilizar fosfatos e inhibir el crecimiento de hongos fitopatógenos (Park, Lee y Son, 2009). Su uso como agente de biocontrol está dado por su capacidad de sintetizar un amplio rango de antibióticos y otros metabolitos secundarios, además de producir cianuro de hidrógeno y sideróforos que pueden inhibir el crecimiento de fitopatógenos (Paulsen et al., 2005).

En relación al tipo de formulación, el mayor porcentaje correspondió a la fórmula sólida, principalmente polvo (incluye polvo seco predominantemente, polvo mojable y polvo de aplicación directa) y suelo. Lo anterior se relaciona con el hecho de que una de las formas de propagación de los hongos micorrízicos arbusculares, se basa en la colocación de esporas o propágulos en un suelo previamente esterilizado y siembra de semilla de una planta micorrícica, para posteriormente utilizarse como un inoculante (aislamiento de 
consorcios de hongos micorrícicos arbusculares de plantas medicinales y su efecto en el crecimiento de vinca) (Catharanthus roseus).

En cuanto a la formulación líquida, la mayoría de inóculos bacterianos se presentan en suspensión concentrada. Los inoculantes líquidos presentan varias ventajas en comparación con los inoculantes sólidos, entre estas su fácil manejo y mayor vida útil. Asimismo, permiten la inclusión de nutrientes, protectores e inductores celulares, y su aplicación se puede hacer por agua de riego, por gravedad o presurizado (Bashan et al., 2014; Bojórquez et al., 2010). De igual manera, el agricultor tiene un mejor control de la cantidad aplicada al manejarse en volumen y no en peso (Bojórquez et al., 2010). En contraste, una de sus desventajas es el almacenamiento en frío para el mantenimiento de su vida útil. Los inoculantes líquidos que contienen concentraciones de $2 \times 10^{9}$ células por $\mathrm{ml}$ son muy comunes, lo que permite bajas tasas de aplicación y mayor eficiencia en su uso (Schulz y Thelen, 2008).

Por último, en referencia a los principales cultivos de aplicación contemplados para los inoculantes biológicos registrados ante el ICA, el arroz se presenta como uno de los más frecuentes. Esto concuerda con Sanjuán Pinilla, el cual manifiesta que el uso de biofertilizantes en Colombia se ha incrementado, especialmente en el sector arrocero (Sanjuán Pinilla y Moreno Sarmiento, 2010). De igual manera, Moreno en su estudio Industria de bioinsumos de uso agrícola en Colombia, reportaron a las hortalizas, algodón y el café como cultivos para los cuales se han desarrollado bioinsumos (Moreno, Rodríguez, Pérez y Buitrago, 2015).

\section{CONCLUSIÓN}

En Colombia, la mayoría de los inoculantes biológicos emplean en 
su formulación hongos micorrízicos del género Glomus y Acaulospora, y la bacteria Azotobacter chroocoocum ampliamente reportados en la literatura por su acción biofertilizante. De igual manera, los inoculantes se caracterizan por sus actividades biológicas varias y por ser dirigidos principalmente al cultivo del arroz.

La producción de inoculantes biológicos se concentra en el departamento de Cundinarma, existiendo una nula producción en la mayoría de departamentos que conforman la región Caribe. Esta situación constituye un reto para los agricultores, empresarios e institutos de investigación del Caribe colombiano en la generación de inoculantes a partir de cepas adaptadas a las propias condiciones.

\section{REFERENCIAS BIBLIOGRÁFICAS}

Accinelli, C., Saccà, M. L., Abbas, H. K., Zablotowicz, R. M. y Wilkinson, J. R. (2009). Use of a granular bioplastic formulation for carrying conidia of a non-aflatoxigenic strain of Aspergillus flavus. Bioresource technology, 100(17), 3997-4004.

Acevedo, E., Galindo-Castaneda, T., Prada, F., Navia, M. y Romero, H. M. (2014). Phosphate-solubilizing microorganisms associated with the rhizosphere of oil palm (Elaeis guineensis Jacq.) in Colombia. Applied Soil Ecology, 80, 26-33.

Acevedo-Sandoval, O., Ortiz-Hernández, E., Cruz-Sánchez, M. y Cruz-Chávez, E. (2004). El papel de óxidos de hierro en suelos. Terra Latinoamericana, 22(4), 485-497.

Agerer, R. (2001). Exploration types of ectomycorrhizae. Mycorrhi$z a, 11(2), 107-114$.

Aguado-Santacruz, G. A., Moreno-Gómez, B., Jiménez-Francisco,

B., García-Moya, E., y Preciado-Ortiz, R. E. (2012). Impacto de los sideróforos microbianos y fitosidéforos en la asimilación de 
hierro por las plantas: una síntesis. Revista fitotecnia mexicana, 35(1), 9-21.

Ahemad, M. y Kibret, M. (2014). Mechanisms and applications of plant growth promoting rhizobacteria: current perspective. Journal of King Saud University-Science, 26(1), 1-20.

Ahmad, F., Ahmad, I. y Khan, M. S. (2008). Screening of free-living rhizospheric bacteria for their multiple plant growth promoting activities. Microbiological research, 163(2), 173-181.

Alberty, R. A. (2005). Thermodynamics of the mechanism of the nitrogenase reaction. Biophysical chemistry, 114(2), 115-120.

Ammani, K. y Rao, A. S. (1996). Effect of two arbuscular mycorrhizal fungi Acaulospora spinosa and A. scrobiculata on upland rice varieties. Microbiological research, 151(3), 235-237.

Aristizábal Sepúlveda, O. L. (2013). Evaluación de la comercialización y mercadeo de los Bioinsumos de uso agrícola registrados en Colombia. Corporación Universitaria Lasallista. Recuperado a partir de http://repository.lasallista.edu.co/dspace/ handle/10567/1539

Artursson, V., Finlay, R. D. y Jansson, J. K. (2006). Interactions between arbuscular mycorrhizal fungi and bacteria and their potential for stimulating plant growth. Environmental microbiology, 8(1), 1-10.

Barbieri, P. y Galli, E. (1993). Effect on wheat root development of inoculation with an Azospirillum brasilense mutant with altered indole-3-acetic acid production. Research in Microbiology, 144(1), 69-75.

Bashan, Y. (1998). Inoculants of plant growth-promoting bacteria for use in agriculture. Biotechnology advances, 16(4), 729-770.

Bashan, Y., de-Bashan, L. E., Prabhu, S. R. y Hernandez, J. P. (2014). Advances in plant growth-promoting bacterial inoculant techno- 
logy: formulations and practical perspectives (1998-2013). Plant and Soil, 378(1-2), 1-33.

Bidondo, L. F., Bompadre, J., Pergola, M., Silvani, V., Colombo, R., Bracamonte, F. y Godeas, A. (2012). Differential interaction between two Glomus intraradices strains and a phosphate solubilizing bacterium in maize rhizosphere. Pedobiologia, 55(4), 227-232.

Bojórquez, A. D. A., Gutiérrez, C. G., Báez, J. R. C., Sánchez, M. Á. A., Montoya, L. G. y Pérez, E. N. (2010). Biofertilizantes en el desarrollo agrícola de México. Ra Ximhai, 6(1), 51-56.

Broughton, W. J., Zhang, F., Perret, X. y Staehelin, C. (2003). Signals exchanged between legumes and Rhizobium: agricultural uses and perspectives. Plant and Soil, 252(1), 129-137.

Buono, N. I. y Ulla, E. L. (2016). Efectos de la inoculación con bacterias solubilizadoras de fosfato en tabaco (Nicotiana tabacum L.) y pimiento (Capsicum annuum L.) en condiciones controladas. Revista agronómica del noroeste argentino, 36(2), 45-54.

Camelo, M., Vera, S. P. y Bonilla, R. R. (2011). Mecanismos de acción de las rizobacterias promotoras del crecimiento vegetal. Corpoica Ciencia y Tecnología Agropecuaria, 12(2), 159-166.

Cowan, M. M. (1999). Plant products as antimicrobial agents. Clinical microbiology reviews, 12(4), 564-582.

De Souza, R., Beneduzi, A., Ambrosini, A., Da Costa, P. B., Meyer, J., Vargas, L. K., Passaglia, L. M. (2013). The effect of plant growth-promoting rhizobacteria on the growth of rice (Oryza sativa L.) cropped in southern Brazilian fields. Plant and soil, 366(1-2), 585-603.

Dell'Amico, J. M., Rodríguez, P., Torrecillas, A., Morte, A., y Sánchez-Blanco, M. de J. (2002). Influencia de la micorrización en el crecimiento y las relaciones hídricas de plantas de tomate so- 
metidas a un ciclo de sequía y recuperación. Cultivos Tropicales, 23(1), 29-34.

Díaz, M. A., Aranza, Y. R., Gallo, A. O., Vega, J. Y., Robles, R. B. y others. (2013). Composición de la economía de la región Caribe de Colombia. Banco de la república-economía regional. Recuperado a partir de: https://ideas.repec.org/p/col/000103/013863. html

Dodd, I. C., Zinovkina, N. Y., Safronova, V. I. y Belimov, A. A. (2010). Rhizobacterial mediation of plant hormone status. Annals of Applied Biology, 157(3), 361-379.

Duponnois, R. y Garbaye, J. (1991). Effect of dual inoculation of Douglas fir with the ectomycorrhizal fungus Laccaria laccata and mycorrhization helper bacteria (MHB) in two bare-root forest nurseries. Plant and Soil, 138(2), 169-176.

Encinas, M. S. y García, L. M. (1997). Diagnóstico visual de la clorosis férrica. ITEA. Producción vegetal, 93(1), 7-22.

Fernández, M. T. y Rodríguez, H. (2005). El papel de la solubilización de fósforo en los biofertilizantes microbianos. Recuperado a partir de: http://repositoriodigital.academica.mx/jspui/ handle/987654321/382595

Fortin, J. A., Bécard, G., Declerck, S., Dalpé, Y., St-Arnaud, M., Coughlan, A. P. y Piché, Y. (2002). Arbuscular mycorrhiza on root-organ cultures. Canadian Journal of Botany, 80(1), 1-20.

Frey-Klett, P., Garbaye, J. y Tarkka, M. (2007). The mycorrhiza helper bacteria revisited. New phytologist, 176(1), 22-36.

Gamalero, E., Trotta, A., Massa, N., Copetta, A., Martinotti, M. G. y Berta, G. (2004). Impact of two fluorescent pseudomonads and an arbuscular mycorrhizal fungus on tomato plant growth, root architecture and P acquisition. Mycorrhiza, 14(3), 185-192.

Glick, B. R. (2012). Plant growth-promoting bacteria: mecha- 
nisms and applications. Scientifica. Recuperado a partir de: https://www.hindawi.com/journals/scientifica/2012/963401 /?viewType=Print\&viewClass=Print

González-Chávez, M. C., Ferrera-Cerrato, R., Villegas-Monter, A. y Oropeza, J. L. (2000). Selección de sustratos de crecimiento en microplántulas de cítricos inoculadas con Glomus sp. Zac-19. Terra, 18(4), 369-377.

Goswami, D., Thakker, J. N. y Dhandhukia, P. C. (2016). Portraying mechanics of plant growth promoting rhizobacteria (PGPR): A review. Cogent Food \& Agriculture, 2(1), 1127-500.

Grageda-Cabrera, O. A., Díaz-Franco, A., Peña-Cabriales, J. J. y Vera-Nuñez, J. A. (2012a). Impacto de los biofertilizantes en la agricultura. Revista mexicana de ciencias agrícolas, 3(6), 1261-1274.

Grageda-Cabrera, O. A., Díaz-Franco, A., Peña-Cabriales, J. J., y Vera-Nuñez, J. A. (2012b). Impacto de los biofertilizantes en la agricultura. Revista mexicana de ciencias agrícolas, 3(6), 1261-1274.

Greenshields, D. L., Liu, G., Feng, J. I. E., Selvaraj, G. y Wei, Y. (2007). The siderophore biosynthetic gene SID1, but not the ferroxidase gene FET3, is required for full Fusarium graminearum virulence. Molecular plant pathology, 8(4), 411-421.

Gurdeep, K. y Reddy, M. S. (2015). Effects of phosphate-solubilizing bacteria, rock phosphate and chemical fertilizers on maize-wheat cropping cycle and economics. Pedosphere, 25(3), 428-437.

Herridge, D. F., Peoples, M. B. y Boddey, R. M. (2008). Global inputs of biological nitrogen fixation in agricultural systems. Plant and Soil, 311(1-2), 1-18.

Hoffman, B. M., Lukoyanov, D., Yang, Z. Y., Dean, D. R. y Seefeldt, L. C. (2014). Mechanism of nitrogen fixation by nitrogenase: the next stage. Chemical reviews, 114(8), 4041-4062. 
Höfte, M., Seong, K. Y., Jurkevitch, E. y Verstraete, W. (1991). Pyoverdin production by the plant growth beneficial Pseudomonas strain 7NSK2: Ecological significance in soil. En Iron Nutrition and Interactions in Plants, 289-297. Springer. Recuperado a partir de http:// link.springer.com/chapter/10.1007/978-94-011-3294-7_35

Instituto Colombiano Agropecuario - ICA. (s. f.). Recuperado 22 de febrero de 2017, a partir de http://www.ica.gov.co/ Jeffries, P., Gianinazzi, S., Perotto, S., Turnau, K. y Barea, J. M. (2003). The contribution of arbuscular mycorrhizal fungi in sustainable maintenance of plant health and soil fertility. Biology and fertility of soils, 37(1), 1-16.

Jones, K. A. y Burges, H. D. (1998). Technology of formulation and application. En Formulation of Microbial Biopesticides, 7-30. Springer. Recuperado a partir de http://link.springer.com/ chapter/10.1007/978-94-011-4926-6_2

Kaiser, K. y Guggenberger, G. (2000). The role of DOM sorption to mineral surfaces in the preservation of organic matter in soils. Organic geochemistry, 31(7), 711-725.

Kaneko, T., Nakamura, Y., Sato, S., Minamisawa, K., Uchiumi, T., Sasamoto, S.,... others. (2002). Complete genomic sequence of nitrogen-fixing symbiotic bacterium Bradyrhizobium japonicum USDA110. DNA research, 9(6), 189-197.

Kavadia, A., Vayenas, D. V., Pavlou, S. y Aggelis, G. (2008). Dynamics of free-living nitrogen-fixing bacterial populations and nitrogen fixation in a two-prey-one-predator system. Ecological modelling, 218(3), 323-338.

Ke, L. I., Jian-jun, X. U., Lu-yao, W., Chu-nan, W., Chen, Y. U. y Jian-hua, G. U. O. (2016). Effects of Acaulospora spinosa on plant growth and lycopene related genes (psy1 and psy2) expression of tomato. Yingyong Shengtai Xuebao, 27(2). Re- 
cuperado a partir de: http://search.ebscohost.com/login. aspx?direct=true \&profile $=$ ehost $\&$ scope $=$ site $\&$ authtype $=-$ crawler\&jrnl=10019332\&AN=114533302\&h=myRca\%2BfAlFO3R6KCbi4KOLotcWWKI2hDYjGTLS7\%2F9Xna5I7tuR3LzPLoSZ70rERhLWw3JCe5tNOD\%2BZXTkztnNg\%3D\%3D\&crl=c Khaitov, B., Patiño-Ruiz, J. D., Pina, T. y Schausberger, P. (2015). Interrelated effects of mycorrhiza and free-living nitrogen fixers cascade up to aboveground herbivores. Ecology and evolution, 5(17), 3756-3768.

Kim, K. Y., Jordan, D. y McDonald, G. A. (1997). Effect of phosphate-solubilizing bacteria and vesicular-arbuscular mycorrhizae on tomato growth and soil microbial activity. Biology and fertility of soils, 26(2), 79-87.

Kızılkaya, R. (2008). Yield response and nitrogen concentrations of spring wheat (Triticum aestivum) inoculated with Azotobacter chroococcum strains. Ecological Engineering, 33(2), 150-156.

Kudoyarova, G. R., Arkhipova, T. N. y Melent'ev, A. I. (2015). Role of bacterial phytohormones in plant growth regulation and their development. En Bacterial metabolites in sustainable agroecosystem, 69-86. Springer. Recuperado a partir de: http://link. springer.com/chapter/10.1007/978-3-319-24654-3_4

Kumar, A., Bahadur, I., Maurya, B. R., Raghuwanshi, R., Meena, V. S., Singh, D. K. y Dixit, J. (2015). Does a plant growth promoting rhizobacteria enhance agricultural sustainability. J Pure Appl Microbiol, 9(1), 715-724.

Liu, H., Yuan, M., Tan, S., Yang, X., Lan, Z., Jiang, Q., Jing, Y. (2015). Enhancement of arbuscular mycorrhizal fungus (Glomus versiforme) on the growth and $\mathrm{Cd}$ uptake by $\mathrm{Cd}$-hyperaccumulator Solanum nigrum. Applied Soil Ecology, 89, 44-49.

Luna Martínez, L., Martínez Peniche, R. A., Hernández Iturriaga, M., 
Arvizu Medrano, S. M., y Pacheco Aguilar, J. R. (2013). Caracterización de rizobacterias aisladas de tomate y su efecto en el crecimiento de tomate y pimiento. Revista fitotecnia mexicana, 36(1), 63-69.

Martínez, L. B. y Pugnaire, F. I. (2009). Interacciones entre las comunidades de hongos formadores de micorrizas arbusculares y de plantas. Algunos ejemplos en los ecosistemas semiáridos. Revista Ecosistemas, 18(2). Recuperado a partir de http://revistaecosistemas.net/index.php/ecosistemas/article/view/65

Meena, V. S., Maurya, B. R. y Verma, J. P. (2014). Does a rhizospheric microorganism enhance $\mathrm{K}+$ availability in agricultural soils? Microbiological research, 169(5), 337-347.

Menéndez, C., Trujillo, L. E., Ramírez, R., González-Peña, D., Espinosa, D., Enríquez, G. A. y Hernández, L. (2014). Production of a liquid Bradyrhizobium japonicum inoculant with high impact on the mechanized sowing of soybean in Cuba. Biotecnología Aplicada, 31(2), 116-120.

Milošević, N., Tintor, B. y Cvijanović, G. (2012). Effect of inoculation with Azotobacter chroococcum on wheat yield and seed quality. En International Conference: Conventional and molecular breeding of field and vegetable crops, Novi Sad, Serbia, (4). Recuperado a partir de: http://www.rombio.eu/rbl3vol17/16.pdf

Mohammadi, K. y Sohrabi, Y. (2012). Bacterial biofertilizers for sustainable crop production: a review. ARPN J Agric Biol Sci, 7(5), 307-316.

Molina, L., Mahecha, L., Medina, S. y others. (2005). Importancia del manejo de hongos micorrizógenos en el establecimiento de árboles en sistemas silvopastoriles. Revista Colombiana de Ciencias Pecuarias, 18(2), 162-175.

Montañez, A., Blanco, A. R., Barlocco, C., Beracochea, M. y Sicardi, 
M. (2012). Characterization of cultivable putative endophytic plant growth promoting bacteria associated with maize cultivars (Zea mays L.) and their inoculation effects in vitro. Applied Soil Ecology, 58, 21-28.

Moreno, D. C. Z., Rodríguez, L. F. R., Pérez, M. V. S. y Buitrago, R. R. B. (2015). Industria de bioinsumos de uso agrícola en Colombia. Revista UDCA Actualidad y Divulgación Científica, 18(1). Recuperado a partir de: http://revistas.udca.edu.co/index.php/ act-div-cientifica/article/view/106

Munkvold, L., Kjøller, R., Vestberg, M., Rosendahl, S. y Jakobsen, I. (2004). High functional diversity within species of arbuscular mycorrhizal fungi. New Phytologist, 164(2), 357-364.

Noda, Y. (2009). Las Micorrizas: Una alternativa de fertilización ecológica en los pastos. Pastos y Forrajes, 32(2), 1-1.

Orr, C. H., James, A., Leifert, C., Cooper, J. M. y Cummings, S. P. (2011). Diversity and activity of free-living nitrogen-fixing bacteria and total bacteria in organic and conventionally managed soils. Applied and environmental microbiology, 77(3), 911-919.

Ortíz-Castro, R., Contreras-Cornejo, H. A., Macías-Rodríguez, L. y López-Bucio, J. (2009). The role of microbial signals in plant growth and development. Plant signaling \& behavior, 4(8), 701-712.

Panzieri, M., Marchettini, N. y Hallam, T. G. (2000). Importance of the Bradhyrizobium japonicum symbiosis for the sustainability of a soybean cultivation. Ecological Modelling, 135(2), 301-310. Park, K.-H., Lee, C.-Y. y Son, H. J. (2009). Mechanism of insoluble phosphate solubilization by Pseudomonas fluorescens RAF15 isolated from ginseng rhizosphere and its plant growth-promoting activities. Letters in applied microbiology, 49(2), 222-228.

Parmar, P. y Sindhu, S. S. (2013). Potassium solubilization by rhizos- 
phere bacteria: influence of nutritional and environmental conditions. Journal of Microbiology Research, 3(1), 25-31.

Pati, B. R., Sengupta, S. y Chandra, A. K. (1995). Impact of selected phyllospheric diazotrophs on the growth of wheat seedlings and assay of the growth substances produced by the diazotrophs. Microbiological Research, 150(2), 121-127.

Paulsen, I. T., Press, C. M., Ravel, J., Kobayashi, D. Y., Myers, G. S., Mavrodi, D. V., others. (2005). Complete genome sequence of the plant commensal Pseudomonas fluorescens Pf-5. Nature biotechnology, 23(7), 873-878.

Pedraza, R. O., Teixeira, K. R., Scavino, A. F., de Salamone, I. G., Baca, B. E., Azcón, R., Bonilla, R. (2010). Microorganismos que mejoran el crecimiento de las plantas y la calidad de los suelos. Revisión. Corpoica Ciencia y Tecnología Agropecuaria, 11(2), 155-164.

Rainey, P. B. (1999). Adaptation of Pseudomonas fluorescens to the plant rhizosphere. Environmental Microbiology, 1(3), 243-257.

Rao, N. S. (2016). Advances in agricultural microbiology. Elsevier. Recuperado a partir de: https://books.google.es/ books?hl=es\&lr=\&id=ho2GDAAAQBAJ\&oi=fnd\&pg =PP1\&d$q=$ Preparation+and+utilization+of+phosphate+biofertilizers $+u$ sing+agricultural + waste\&ots=9UIXUuko8v\&sig=6ZDbYQvQynwPwzbQFF5XxFSyR1s

Raupach, G. S. y Kloepper, J. W. (1998). Mixtures of plant growth-promoting rhizobacteria enhance biological control of multiple cucumber pathogens. Phytopathology, 88(11), 1158-1164.

Reddy, C. A. y Saravanan, R. S. (2013). Polymicrobial multi-functional approach for enhancement of crop productivity. Adv Appl Microbiol, 82, 53-113.

Rodríguez, H. y Fraga, R. (1999). Phosphate solubilizing bacteria 
and their role in plant growth promotion. Biotechnology advances, 17(4), 319-339.

Rosset, P. M. R., R González, W., Hruska, A. J., Calvacanti, J. S. B., Kijne, J. W., Hargreaves, G. H., others. (2011). El estado de los recursos de tierras y aguas del mundo para la alimentación y la agricultura: la gestión de los sistemas en situación de riesgoThe state of the world's land and water resources for food and agriculture. FAO, Roma (Italia) Mundi-Prensa (España). Recuperado a partir de: http://www.sidalc.net/cgi-bin/wxis.exe/?lsisScrip$\mathrm{t}=$ ORTON.xis\&B1=Buscar\&formato $=1 \&$ cantidad $=50 \&$ expresion $=$ REGADIO

Sanjuán Pinilla, J. y Moreno Sarmiento, N. (2010). Aplicación de insumos biológicos: una oportunidad para la agricultura sostenible y amigable con el medioambiente. Revista Colombiana de Biotecnología, 12(1), 4-7.

Santi, C., Bogusz, D. y Franche, C. (2013). Biological nitrogen fixation in non-legume plants. Annals of botany, 111(5), 743-767.

Schulz, T. J. y Thelen, K. D. (2008). Soybean seed inoculant and fungicidal seed treatment effects on soybean. Crop science, 48(5), 1975-1983.

Sethi, S. K. y Adhikary, S. P. (2012). Azotobacter: a plant growth-promoting rhizobacteria used as biofertilizer. Dynamic Biochemistry, Process Biotechnology and Molecular Biology, 6(1), 68-74.

Shridhar, B. S. (2012). Review: nitrogen fixing microorganisms. International Journal of Microbiological Research, 3(1), 4-52.

Sierra, B. E. G. (2008). Micorriza arbuscular. Recurso microbiológico en la agricultura sostenible. Tecnología en Marcha, 21(1), 191-201.

Solomon, T., Pant, L. M. y Angaw, T. (2012). Effects of inoculation by Bradyrhizobium japonicum strains on nodulation, nitrogen 
fixation, and yield of soybean (Glycine max L. Merill) varieties on nitisols of Bako, Western Ethiopia. ISRN Agronomy, 2012. Recuperado a partir de http://downloads.hindawi.com/journals/ isrn.agronomy/2012/261475.pdf

Stephens, J. H. G. y Rask, H. M. (2000). Inoculant production and formulation. Field Crops Research, 65(2), 249-258.

Taylor, A., Walker, C. y Bending, G. D. (2014). Dimorphic spore production in the genus Acaulospora. Mycoscience, 55(1), 1-4.

Tien, T. M., Gaskins, M. H. y Hubbell, D. H. (1979). Plant growth substances produced by Azospirillum brasilense and their effect on the growth of pearl millet (Pennisetum americanum L.). Applied and Environmental Microbiology, 37(5), 1016-1024.

Toro, M., Bazó, I. y López, M. (2008). Micorrizas arbusculares y bacterias promotoras de crecimiento vegetal, biofertilizantes nativos de sistemas agrícolas bajo manejo conservacionista. Agronomía Tropical, 58(3), 215-221.

Treseder, K. K. (2004). A meta-analysis of mycorrhizal responses to nitrogen, phosphorus, and atmospheric $\mathrm{CO} 2$ in field studies. New Phytologist, 164(2), 347-355.

Tsvetkov, I., Dzhambazova, T., Kondakova, V., y Batchvarova, R. (2014). Mycorrhizal fungi Glomus spp. and Trichoderma spp. in viticulture (review). Bulgarian Journal of Agricultural Science, 20(4), 849-855.

Vega-Celedón, P., Canchignia Martínez, H., González, M. y Seeger, M. (2016). Biosíntesis de ácido indol-3-acético y promoción del crecimiento de plantas por bacterias. Cultivos Tropicales, 37, 33-39.

Vejan, P., Abdullah, R., Khadiran, T., Ismail, S. y Nasrulhaq Boyce, A. (2016). Role of plant growth promoting rhizobacteria in agricultural sustainability-a review. Molecules, 21(5), 573. 
Vessey, J. K. (2003). Plant growth promoting rhizobacteria as biofertilizers. Plant and soil, 255(2), 571-586.

Wang, H., Shen, L. I. U., Zhai, L., Zhang, J., Ren, T., Fan, B. y Liu, $H$. (2015). Preparation and utilization of phosphate biofertilizers using agricultural waste. Journal of Integrative Agriculture, 14(1), 158-167.

Wang, M., Zheng, Q., Shen, Q. y Guo, S. (2013). The critical role of potassium in plant stress response. International Journal of Molecular Sciences, 14(4), 7370-7390.

Wani, S. A., Chand, S., Wani, M. A., Ramzan, M. yHakeem, K. R. (2016). Azotobacter chroococcum-A Potential Biofertilizer in Agriculture: An Overview. En Soil Science: Agricultural and Environmental Prospectives, 333-348. Springer. Recuperado a partir de: http:// link.springer.com/chapter/10.1007/978-3-319-34451-5_15

Wani, S. A., Chand, S. y Ali, T. (2013). Potential use of Azotobacter chroococcum in crop production: an overview. Current Agriculture Research Journal, 1(1), 35-38.

Wittwer, S. (2016). An Overview of Agricultural Microbiology. Advances In Agricultural Microbiology. Recuperado a partir de: https://books.google.es/books?hl=es\&lr=\&id=ho2GDAAAQBAJ\&oi=fnd\&pg $=P R 17 \& d q=A n+$ Overview + of +Agricultural+Microbiology+\&ots=9UIXUukt8A\&sig =mtUiCK4FZbu8JZZd ma06ntXMBxE

Wong, W. S., Tan, S. N., Ge, L., Chen, X., y Yong, J. W. H. (2015). The importance of phytohormones and microbes in biofertilizers. En Bacterial metabolites in sustainable agroecosystem, 105-158. Springer. Recuperado a partir de: http://link.springer. com/chapter/10.1007/978-3-319-24654-3_6

Wu, Q.-S., Zou, Y. N., Xia, R. X. y Wang, M. Y. (2007). Five Glomus species affect water relations of Citrus tangerine during drought 
stress. Bot Stud, 48(2), 147-154.

Xie, Z. P., Staehelin, C., Vierheilig, H., Wiemken, A., Jabbouri, S., Broughton, W. J., Boller, T. (1995). Rhizobial nodulation factors stimulate mycorrhizal colonization of nodulating and nonnodulating soybeans. Plant Physiology, 108(4), 1519-1525.

Zhan, J. y Sun, Q. (2011). Diversity of free-living nitrogen-fixing microorganisms in wastelands of copper mine tailings during the process of natural ecological restoration. Journal of Environmental Sciences, 23(3), 476-487.

Zörb, C., Senbayram, M. y Peiter, E. (2014). Potassium in agriculture-status and perspectives. Journal of Plant Physiology, 171(9), 656-669.

\footnotetext{
Cómo citar en este capítulo

Pérez Lavalle, L., Bolívar Anillo, H. J., \& Díaz Pérez, A. (2017). Biofertilizantes en Colombia. En H. H. Estrada-López, H. G. Saumett-España, M. A. Iglesias-Navas, M. J. Bahamón, A. M. Cáceres-Martelo, C. E. Restrepo Flórez, ... A. Díaz Pérez, Productos de confitería nutracéutica. Una opción empresarial para cultivadores de frutas y hortalizas (pp.179-222). Barranquilla: Universidad Simón Bolívar.
} 